\title{
HISTOPATHOLOGICAL SPECTRUM OF HYSTERECTOMY SPECIMENS- A RETROSPECTIVE ANALYSIS AT IGIMS, PATNA, BIHAR
}

\author{
Zeenat Sarmadi Imam¹, Kalpana Chandra ${ }^{2}$, Monalisa $^{3}$, Bipin Kumar 4 , Anshuman Sinha ${ }^{5}$, Anju Singh 6 , Sanjeet Kumar Singh 7 , \\ Shuchismita ${ }^{8}$
}

${ }^{1}$ Senior Resident, Department of Pathology, IGIMS, Patna, Bihar, India. 2 Assistant Professor, Department of Pathology, IGIMS, Patna, Bihar, India. 3Senior Resident, Department of Pathology, IGIMS, Patna, Bihar, India. ${ }^{4}$ Professor, Department of Pathology, IGIMS, Patna, Bihar, India. ${ }^{5}$ Senior Resident, Department of Pathology, IGIMS, Patna, Bihar, India. ${ }^{6}$ Associate Professor, Department of Pathology, IGIMS, Patna, Bihar, India. ${ }^{7}$ Associate Professor, Department of Pathology, IGIMS, Patna, Bihar, India. ${ }^{8}$ Assistant Professor, Department of Pathology, IGIMS, Patna, Bihar, India.

\section{BACKGROUND}

ABSTRACT

Uterus is subjected to many benign and malignant diseases, which are managed by medical and surgical methods. In this study we analysed the spectrum of morphological changes noted in the hysterectomy specimen received in our department. We also emphasised the relevance of histopathology in every case and highlighted any incidental findings including non-neoplastic and neoplastic lesions.

\section{MATERIALS AND METHODS}

This is a retrospective descriptive study. We included a total of 220 hysterectomy samples received in the Pathology Department of Indira Gandhi Institute of Medical Sciences from January 2015 to December 2016. Cases were selected as per inclusion and exclusion criteria. All the details were collected from histopathology request form and hospital record sheet. Gross and microscopic features were analysed and recorded.

\section{RESULTS}

We included a total of 220 hysterectomy specimens. 161 cases had undergone total abdominal hysterectomy and 59 cases had undergone simple hysterectomy. The most common age group was in the age range of $41-50$. The most common pathological findings in the myometrium was leiomyoma (29.04\%) followed by adenomyosis (11.69\%). In cervix, the common histopathological finding was chronic cervicitis (91.81\%). Squamous cell carcinoma in cervix was 6.36\%. In ovaries, non-neoplastic cystic lesions were in $10 \%$ cases. Other benign tumours include mature cystic teratoma (1.81\%), mucinous cystadenoma (1.81\%) and serous cystadenoma (4.09\%). In malignant counterpart, serous cystadenocarcinoma and mucinous cystadenocarcinoma are $4.09 \%$ and $1.81 \%$ respectively. One case of collision tumour and one case of Krukenberg tumour were noted.

\section{CONCLUSION}

Hysterectomy is a treatment modality for benign as well as malignant clinical conditions. The increasing incidences of malign ant neoplasm of various sites of female genital tract emphasise the relevance of histopathological analysis of all surgical specimens, which can aid in further management and prognostication.

\section{KEY WORDS}

Histopathology, Hysterectomy, Leiomyoma.

HOW TO CITE THIS ARTICLE: Imam ZS, Chandra K, Monalisa, et al. Histopathological spectrum of hysterectomy specimens- a retrospective analysis at IGIMS, Patna, Bihar. J. Evolution Med. Dent. Sci. 2018;7(30):3352-3355, DOI: 10.14260/jemds/2018/756

\section{BACKGROUND}

Hysterectomy is the most commonly performed major gynaecological surgery throughout the world.[1] Uterus is subjected to many benign and malignant diseases and for this many treatment options are available including medical and conservative surgical. Hysterectomy remains as one of the most successful operations in terms of symptoms relief,

'Financial or Other Competing Interest': None.

Submission 11-06-2018, Peer Review 08-07-2018,

Acceptance 14-07-2018, Published 23-07-2018.

Corresponding Author:

Dr. Kalpana Chandra,

Assistant Professor, Department of Pathology,

Indira Gandhi Institute of Medical Sciences,

Patna-800014, Bihar, India.

E-mail: kalpana_chandra_14@yahoo.co.in

DOI: $10.14260 /$ jemds $/ 2018 / 756$

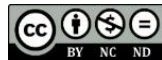

patient's satisfaction, improvement in quality of life and providing definite cure to many non-neoplastic lesions of uterus such as fibroids, dysfunctional uterine bleeding, uterine prolapse, endometriosis, adenomyosis etc.[2] At many times, hysterectomy has been proved as life-saving procedure. On the top of above-mentioned justification for hysterectomy, a substantial increase in hysterectomies has been noted owing to the prophylaxis against uterine cancer. Histopathological study of specimen remains the gold standard, as it carries diagnostic as well as therapeutic significance. It also aids in planning management of malignant lesion if found any.

In this study, we want to discuss the histomorphological spectrum of lesions in the hysterectomy specimen received at our institute. We also want to emphasise on the relevance of histopathology in every case and highlight any incidental findings including non-neoplastic and neoplastic lesions. 


\section{Aims and Objectives}

- To study the morphological spectrum of histopathological lesions detected and their relative frequency in hysterectomy specimens.

- To study the various incidental organic pathological lesions in the hysterectomy specimens.

\section{MATERIALS AND METHODS}

This is a retrospective descriptive study conducted at Department of Pathology, IGIMS, Patna, Bihar. We included a total of 220 hysterectomy samples operated for gynaecological aetiology and received in the Pathology Department of Indira Gandhi Institute of Medical Sciences from January 2015 to December 2016. Cases were selected as per the following inclusion and exclusion criteria.

\section{Inclusion Criteria}

Uterus with cervix specimens obtained by total abdominal hysterectomy, vaginal hysterectomy and hysterectomy with unilateral salpingo-oophorectomy were included.

\section{Exclusion Criteria}

Hysterectomy cases received for slide review without gross specimen were excluded from the study.

After selecting the cases as per inclusion and exclusion criteria, all the details were collected from histopathology request form and hospital record sheet. Gross and microscopic features were recorded and analysed.

\section{RESULTS}

We included a total of 220 hysterectomy specimens received during the study period in our department. We analysed clinical, surgical and histopathological details. Results are summarised as follows:

1. Out of 220 , total abdominal hysterectomy was done in 161 cases and 59 cases had undergone simple hysterectomy.

2. Age-wise distribution (Table 1)- The most common age group undergoing hysterectomy was in the age range of $41-50$.

\begin{tabular}{|c|c|c|c|}
\hline Sl. No. & Age Limit & No & Percentage \\
\hline 1 & $10-20$ & 2 & $0.9 \%$ \\
\hline 2 & $21-30$ & 10 & $4.55 \%$ \\
\hline 3 & $31-40$ & 50 & $22.75 \%$ \\
\hline 4 & $41-50$ & 98 & $44.55 \%$ \\
\hline 5 & $51-60$ & 49 & $22.27 \%$ \\
\hline 6 & $61-70$ & 11 & $5 \%$ \\
\hline \multicolumn{4}{|c|}{ Table 1. Age-Wise Distribution } \\
\hline
\end{tabular}

1) Histomorphological pattern of lesion in endometrium (Table-2)- The endometrium was largely unremarkable in most of the cases $(75 \%)$. In our study, the most significant finding was adenocarcinoma of the endometrium (5\%).

\begin{tabular}{|c|c|c|c|}
\hline Sl. No. & Endometrial Lesion & No. & Percentage \\
\hline 1 & Normal histology & 165 & $75 \%$ \\
\hline 2 & Atrophic endometrium & 27 & $12.2 \%$ \\
\hline 3 & $\begin{array}{c}\text { Disordered proliferative } \\
\text { endometrium }\end{array}$ & 4 & $1.82 \%$ \\
\hline 4 & Endometrial polyp & 7 & $3.18 \%$ \\
\hline 5 & Simple hyperplasia & 4 & $1.82 \%$ \\
\hline
\end{tabular}

\begin{tabular}{|c|c|c|c|}
\hline 6 & Complex hyperplasia & 2 & $0.9 \%$ \\
\hline 7 & Endometrial carcinoma & 11 & $5 \%$ \\
\hline \multicolumn{3}{|c|}{ Table 2. Histomorphological Pattern of Lesion in } \\
Endometrium \\
\hline
\end{tabular}

2) Histomorphological lesion in myometrium (Table-3)The myometrium is largely unremarkable in about half of the cases studied (50.45\%). The most common pathological finding was leiomyoma followed by adenomyosis.

\begin{tabular}{|c|c|c|c|}
\hline Sl. No. & Myometrial Lesions & No. & Percentage \\
\hline 1 & Unremarkable & 111 & $50.45 \%$ \\
\hline 2 & Leiomyoma & 64 & $29.09 \%$ \\
\hline 3 & Adenomyosis & 25 & $11.36 \%$ \\
\hline 4 & Adenomyosis and leiomyoma & 13 & $5.90 \%$ \\
\hline 5 & Granulomatous inflammation & 1 & $0.45 \%$ \\
\hline 6 & Leiomyosarcoma & 2 & $0.90 \%$ \\
\hline 7 & Metastasis & 3 & $1.36 \%$ \\
\hline \multicolumn{2}{|c|}{ Table 3. Histomorphological Lesions in Myometrium } \\
\hline
\end{tabular}

3) Histomorphological lesions in cervix (Table-4)- In cervix, the common histopathological finding was chronic cervicitis. We experienced 14 cases of squamous cell carcinoma and 2 cases of adenocarcinoma.

\begin{tabular}{|c|c|c|c|}
\hline Sl. No. & Cervical Lesions & No. & \% \\
\hline 1 & Chronic cervicitis & 156 & $70.90 \%$ \\
\hline 2 & $\begin{array}{c}\text { Chronic cervicitis with squamous } \\
\text { metaplasia }\end{array}$ & 17 & $7.73 \%$ \\
\hline 3 & $\begin{array}{c}\text { Chronic cervicitis with squamous } \\
\text { metaplasia and nabothian follicle. }\end{array}$ & 29 & $13.18 \%$ \\
\hline 4 & Endocervical polyp & 1 & $0.45 \%$ \\
\hline 5 & Cervical intraepithelial neoplasia (III) & 2 & $0.9 \%$ \\
\hline 6 & Squamous cell carcinoma & 14 & $6.36 \%$ \\
\hline 7 & Adenocarcinoma & 1 & $0.45 \%$ \\
\hline \multicolumn{3}{|c|}{ Table 4. Histomorphological Lesions in Cervix } \\
\hline
\end{tabular}

4) Histomorphological lesions in ovary (Table-5)- In ovary also, we observed varied histological findings. Bilateral ovaries were removed in 101 with preservation of right ovary in 23 cases and preservation of left ovaries in 37 cases.

\begin{tabular}{|c|c|c|c|}
\hline Sl. No. & Ovarian Lesion & No. & \% \\
\hline 1 & Normal & 101 & $45.90 \%$ \\
\hline 2 & Non-neoplastic cystic lesion & 22 & $10 \%$ \\
\hline 3 & Granulomatous oophoritis & 1 & $0.45 \%$ \\
\hline 4 & Ovarian endometriosis & 2 & $0.90 \%$ \\
\hline 5 & Benign serous cystadenoma & 9 & $4.09 \%$ \\
\hline 6 & Benign mucinous cystadenoma & 4 & $1.81 \%$ \\
\hline 7 & Mature cystic teratoma & 4 & $1.81 \%$ \\
\hline 8 & $\begin{array}{c}\text { Malignant serous } \\
\text { cystadenocarcinoma }\end{array}$ & 9 & $4.09 \%$ \\
\hline 9 & $\begin{array}{c}\text { Malignant mucinous } \\
\text { cystadenocarcinoma }\end{array}$ & 4 & $1.81 \%$ \\
\hline 10 & Collision tumour & 1 & $0.45 \%$ \\
\hline 11 & Dysgerminoma & 1 & $0.45 \%$ \\
\hline 12 & Metastatic lesion & 1 & $0.45 \%$ \\
\hline \multicolumn{4}{|c|}{ Table 5. Histomorphological Lesions in Ovary } \\
\hline
\end{tabular}

5) Histomorphological findings in fallopian tubes (Table-6)- Bilateral tubes are largely unremarkable in 
$36.36 \%$ of cases and the significant finding was dysplasia and metastatic deposit in both the tubes.

\begin{tabular}{|c|c|c|c|}
\hline Sl. No. & Fallopian Tubes (Rt + Lt) & No. & $\%$ \\
\hline 1 & Bilateral normal histology & 80 & 36.36 \\
\hline 2 & Rt., Lt. FT- Normal histology & 19,31 & $8.6,14.09$ \\
\hline 3 & Bilateral chronic salpingitis & 19 & 8.6 \\
\hline 4 & Right FT-Hydrosalpinx & 1 & 0.45 \\
\hline 5 & Left FT- Hydrosalpinx & 2 & 0.90 \\
\hline 6 & Bilateral TB granuloma & 1 & 0.45 \\
\hline 7 & Right FT- Dysplasia & 1 & 0.45 \\
\hline 8 & Right FT- Metastatic & 3 & 1.36 \\
\hline 9 & Left FT- Metastatic & 2 & 0.90 \\
\hline 10 & Bilateral- Metastatic & 2 & 0.90 \\
\hline Table 6. Histomorphological Findings in Fallopian Tubes \\
\hline \multicolumn{4}{|c}{}
\end{tabular}

\section{DISCUSSION}

Prevalence of uterine and adnexal pathologies show geographical influence country to country and racial variation within the same country. It has been found that majority of hysterectomies are performed for benign conditions. [3] The present study is aimed at a detailed histopathological evaluation of all lesions of hysterectomy specimens in a tertiary care hospital at Patna from January 2015 to December 2016.

Total abdominal hysterectomy was done in 161 cases and 59 cases had undergone simple hysterectomy in 220 cases. Out of 161 patients 101 underwent bilateral salpingooophorectomies, whereas 23 underwent left salpingooophorectomy with preservation of right adnexa and 37 with right salpingo-oophorectomy with preservation of left adnexa. In cases that underwent simple hysterectomy, only 9 patients $(4.09 \%)$ were operated by vaginal route for prolapse. This was close to what was found by Zaid et al[4] (5.2\%) and less than the findings reported by Butt et al[5] (11\%). One young 18 years old female underwent total abdominal hysterectomy, as she had bicornuate uterus.

The most common age group undergoing hysterectomy includes 41 - 50 age range (44.55\%) followed by 31 - 40 age range $(22.75 \%)$. The incidence was lowest at extremes of age. This age incidence is in concordance with study conducted by Parveen $S$ et al,[6] Vandana et al,[7] Vijay Sreedhar V et al[8] and Medhi $P$ et al.[9]

In the present study, atrophic endometrium was found in $12.2 \%$. Rather GR et al[10] observed $5.44 \%$ cases of atrophic endometrium. A significant high incidence of atrophic endometrium were reported by Jha $\mathrm{R}$ et al[11] (26.2\%) and Medhi $\mathrm{P}$ et al[9] (22.7\%). Endometrial polyp constituted the most common benign lesion (3.18\%). The disordered proliferative endometrium and simple hyperplasia each showed an incidence of $1.82 \%$. 2 cases $(0.9 \%)$ were reported as complex hyperplasia. Rather GR et al[10] found $1.14 \%$ each of disordered proliferative endometrium and complex hyperplasia and a bit higher incidence of simple hyperplasia (3.29\%). It might be because of subjective variation in the interpretation of hyperplasia.

The most significant finding in our analysis was significant number of cases of endometrial endometrioid adenocarcinoma (5\%). It might be because our hospital is a tertiary care centre as well as regional cancer centre of Bihar. Medhi $\mathrm{P}$ et al[9] found no case of endometrial carcinoma, whereas Jha $\mathrm{R}$ et al[11] found 2 cases of endometrial carcinoma and 1 case of endometrial sarcoma and Parveen
S[6] et al found 3 cases of endometrial carcinoma. Gupta A et al[12] found 4 cases of endometrial adenocarcinoma (2.9\%).

Myometrial findings include leiomyoma, adenomyosis and coexistence of both lesions. Leiomyoma was the most common histopathological finding, which constituted 29.04\%. The incidence of leiomyoma in our study was comparable with Jha $\mathrm{R}$ et al[11] (27.1\%) and Parveen S et al[6] (29\%). A bit higher incidence of leiomyoma was observed by Jamal S et al[13] (35.7\%) and Tan XJ et al[14] (56.2\%), but they also concluded leiomyoma to be the most common lesion for surgical intervention. We observed adenomyosis in $11.69 \%$ cases. Adenomyosis was the most common incidental findings in the hysterectomy specimen, as patients do not present with any specific symptoms for this. Results of adenomyosis in our study and by Parveen S et al,[6] (12.3\%) were almost in concordance. Others have reported a bit higher incidence such as Jha $\mathrm{R}$ et al[11] (17.2\%), Medhi $\mathrm{P}$ et al[9] (26\%). We found 5.90\% cases having both leiomyoma and adenomyosis occurring together. Qamar et al[15] and Zaid et al ${ }^{[2]}$ found $5.6 \%$ and $6.4 \%$ respectively the coexistence of leiomyoma and adenomyosis in their study. The next finding in our analysis was well-formed epithelioid granulomas in the myometrium in 1 case and metastatic deposit from one case of Krukenberg tumour and 2 cases of malignant tumour of ovary. We documented 2 cases $(0.9 \%)$ of primary leiomyosarcoma of the myometrium. Zaid et al[2] have reported $0.4 \%$ of leiomyosarcoma.

We found chronic cervicitis in $70.90 \%$ followed by chronic cervicitis with squamous metaplasia and nabothian follicles in $13.18 \%$ and chronic cervicitis with squamous metaplasia in $7.73 \%$ making altogether incidence of chronic cervicitis to $91.81 \%$, which was close to what was found by Jha $\mathrm{R}$ et $\mathrm{al}[11]$ (96.3\%) and Rather GR et al[10] (89.39\%), thereby making this as the most common histological finding. The reason behind this high incidence of chronic cervicitis is that in our institute no cervical biopsy is reported as normal, as few chronic inflammatory cells are always found which is also mentioned by Jha $\mathrm{R}$ et al.[11]

One case of granulomatous inflammation was noted, which was later confirmed as tuberculosis. Cervical tuberculosis is a bit rare finding and is usually secondary to disseminated tuberculosis. We experienced 14 cases of squamous cell carcinoma (6.36\%), 2 cases of adenocarcinoma and CIN III in 2 cases. In a study conducted by Zaid et al[4] and Gousia RR et al,[16] the incidence of invasive squamous cell carcinoma are $0.9 \%$ and $0.3 \%$ respectively which was significantly less than ours.

Ovaries were histologically unremarkable in significant number of cases $(45.90 \%$. The most common findings in ovaries were non-neoplastic cystic lesions $(10 \%)$. We found 2 cases $(0.9 \%)$ of ovarian endometriosis, which was similar to that seen by Gousia et al[16] $(0.61 \%)$. Benign tumours including serous and mucinous cystadenoma accounted for 13 cases and their malignant counterpart was also observed in 13 cases. In benign as well as malignant counterpart, serous tumours accounted for the significant number (4.09\%) and was the commoner than mucinous cystadenocarcinoma. Similar observation was made by Medhi $P$ et al. [9] In the present study, one young 16 years old female underwent bilateral salpingo-oophorectomy and her histopathology confirmed bilateral dysgerminoma. We had one case of collision tumour in 50 years old female and the 
histopathology was papillary serous cystadenocarcinoma in left ovary and in right ovary squamous cell carcinoma arising from dermoid cyst and foci of papillary serous cystadenocarcinoma. We documented one case of metastatic Krukenberg's tumour. In fact this tumour has metastasised to cervix, myometrium and bilateral tubes and the primary was in the colon. The pathology reported in the fallopian were chronic salpingitis in 19 cases, hydrosalpinx in Rt and Lt tubes 1 and 2 each respectively, tubercular granuloma (1 case), dysplasia (1) and metastasis (7) predominantly from ovarian neoplasm.

\section{CONCLUSION}

Hysterectomy is a treatment modality for benign as well as malignant clinical conditions. The increasing incidences of malignant neoplasm of various sites of female genital tract emphasise the relevance of histopathological analysis of all surgical specimens, which can aid in further management and prognostication. We expect that with modern treatment protocols, and understanding the importance of keeping the uterus after completing the family may lower the incidence of hysterectomy for benign lesion, unless it interferes with quality of life.

\section{REFERENCES}

[1] Wu JM, Wechter ME, Geller EJ, et al. Hysterectomy rates in the United States, 2003. Obstet Gynaecol 2007;110(5):1091-5.

[2] Nausheen F, Iqbal J, Bhatti FA, et al. Hysterectomy: the patient's perspective. Annals of Gynecology 2004;10(4):339-41.

[3] Leung PL, Tsang SW, Yuen PM, et al. An audit on hysterectomy for benign diseases in public hospitals in Hong Kong. Hong Kong Med J 2007;13(3):187-93.

[4] Zaid SMO, Thabet MAB. Histopathological findings in hysterectomy specimens: a retrospective study. Middle East J Int Med 2017;10(1):17-24.

[5] Butt JL, Jeffery ST, Van der Spuy ZM. An audit of indications and complications associated with elective hysterectomy at a public service hospital in South Africa. Int J Gynaecol Obstet 2012;116(2):1126.
[6] Parveen S, Tayyab S. A clinicopathological review of elective abdominal hysterectomy. Journal of Surgery Pakistan 2008;13(1):26-9.

[7] Sreedhar VV, Jyothi, Sailja V, et al. Histopathological spectrum of lesions of hysterectomy specimens - a study of 200 cases. Saudi J Pathol \& Microbiol 2016;1(2):54-9.

[8] Gangadharan V, Prasanthi C. Hysterectomy-a clinicopathological correlation in rural setting. Indian J of Basic and Applied Medical Research 2016;5(2):8-15.

[9] Medhi P, Dowerah S, Borgohain D. A histopathological audit of hysterectomy: experience at a tertiary care teaching hospital. International J of Contemporary Medical Research 2016;3(4):1226-8.

[10] Rather GR, Gupta Y, Bardhwaj S. Patterns of lesions in hysterectomy specimens: a prospective study. J K Science 2013;15(2)63-8.

[11] Jha R, Pant AD, Jha A, et al. Histopathological analysis of hysterectomy specimens. JNMA J Nepal Med Assoc 2006;45(163):283-90.

[12] Histopathological spectrum of uterus and cervix in hysterectomy specimens. Int J Med Res Prof 2016;2(3):136-9.

[13] Jamal S, Baqai S. A clinicohistopathological analysis of 260 hysterectomies Pakistan J Pathol 2001;12(2):114.

[14] Tan XJ, Lang JH, Shen K, et al. Operative approaches, indications and medical economics evaluations of 4180 cases of hysterectomy. Zhongguo Yi Xue Ke Xue Yuan Xue Bao 2003;25(4): 406-9.

[15] Shaikh TA, Fatima M, Zehra M. Hysterectomies: an audit at tertiary care hospital. Professional Med J 2011;18(1):45-50.

[16] Gousia RR, Yudhvir G, Subash B. Patterns of lesion in hysterectomy specimens: a prospective study. JK Science 2013;15(2). 